\title{
Territorialidades da(s) cracolândia(s)em São Paulo e no Rio de Janeiro
}

Territorialities of the cracolândia(s) in São Paulo and Rio de Janeiro

\section{Heitor Frúgoli Junior e Mariana Cavalcanti}

\section{(2) OpenEdition \\ 12 Journals}

Edição electrónica

URL: http://journals.openedition.org/aa/561

DOI: $10.4000 /$ aa. 561

ISSN: 2357-738X

Editora

Programa de Pós-Graduação em Antropologia Social (UnB)

\section{Edição impressa}

Data de publição: 31 dezembro 2013

Paginação: 73-97

ISSN: 0102-4302

\section{Refêrencia eletrónica}

Heitor Frúgoli Junior e Mariana Cavalcanti, «Territorialidades da(s) cracolândia(s)em São Paulo e no Rio de Janeiro», Anuário Antropológico [Online], v.38 n.2 | 2013, posto online no dia 01 fevereiro 2014, consultado o 28 abril 2021. URL: http://journals.openedition.org/aa/561 ; DOI: https://doi.org/ 10.4000/aa.561

Este documento foi criado de forma automática no dia 28 abril 2021.

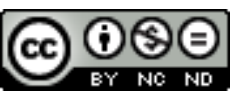

Anuário Antropológico is licensed under a Creative Commons Atribuição-Uso Não-Comercial-Proibição de realização de Obras Derivadas 4.0 International. 


\section{Territorialidades da(s) cracolândia(s)em São Paulo e no Rio de Janeiro}

Territorialities of the cracolândia(s) in São Paulo and Rio de Janeiro

Heitor Frúgoli Junior e Mariana Cavalcanti

\section{NOTA DO EDITOR}

Recebido em 09/10/2013

Aceito em 20/11/2013

1 O crescente uso do crack no Brasil - que desperta várias inquietações, com tentativas de compreensão, diagnóstico e ação que abrangem diversos campos do saber - envolve uma faceta recorrente: a visibilidade de tais práticas em espaços públicos de diversas cidades brasileiras. ${ }^{1}$ Inicialmente assim nomeada em São Paulo, a chamada cracolândia ${ }^{2}$ tem se tornado um termo generalizado (e em certas cidades, já usado no plural), o que exige uma significativa atenção quanto à sua polissemia. Isso ocorre, guardadas as proporções no tempo e no espaço, com outros termos já consagrados nas ciências sociais, como favela ou periferia, que remetem a conjunções de espacialidades, processos de longa duração, representações, relações e narrativas que exigem recortes e delimitações constantes para o devido enfrentamento de um possível excesso de significados (Durham, 2004 [1986]; Frúgoli Jr., 2005; Valladares, 2005; Cavalcanti, 2009).

O presente artigo busca contribuir para os debates sobre o tema - cada vez mais presente na agenda das políticas públicas, a depender de um enfrentamento intersetorial de considerável complexidade - do ponto vista de um desvendamento etnográfico e antropológico, abordando e confrontando como isso tem se manifestado nas duas maiores metrópoles brasileiras, São Paulo e Rio de Janeiro. Ao mesmo tempo, é nossa intenção buscar avançar no modo como tais processos podem cooperar para a capacidade de se lançar um olhar antropológico atento e preciso sobre determinadas 
dinâmicas relacionais e espaciais urbanas. ${ }^{3}$ A ênfase na reconstituição etnográfica (neste artigo, bastante sintetizada) busca ressaltar a importância de compreensão de determinadas interações, envolvendo os próprios usuários de $\mathrm{crack}^{4}$ - em geral nomeados (e estigmatizados) pelas populações locais como noias (em São Paulo), cracudos ou craqueiros (no Rio de Janeiro) - bem como outros agentes diretamente envolvidos com eles, para uma reconstituição de relações mesmo onde não se consegue entrever, num olhar mais distanciado, alguma humanidade.

3 Sem pretendermos aqui uma abordagem fundada na ideia de difusão ou proliferação, ${ }^{5}$ pode-se perceber que o fenômeno que viria a ser reconhecido por diversos atores e agentes sociais como cracolândia ganhou uma visibilidade inicial significativa em São Paulo, em decorrência de usos do crack desde o início da década de 1990, o que se tornou aos poucos bastante denso e visível nas ruas da região da Luz, que veio a ser popularmente conhecida com tal nome, ampliado pelos próprios meios de comunicação, e bastante adotado como contraponto ao polêmico projeto Nova Luz, lançado pela prefeitura, mas concretizado apenas parcialmente (embora com impactos urbanos consideráveis) a partir de meados da década passada (Frúgoli Jr. \& Spaggiari, 2010).

4 Em janeiro de 2012, uma nova tentativa policial sistemática de expulsar os usuários de crack da mencionada área ganhou uma abrangência nacional, cuja amplitude da repressão - que, como de costume, não atingiu os resultados almejados - suscitou uma série de desdobramentos, enfrentamentos e debates ligados à proposta das internações involuntárias, ativismos de várias ordens pelos direitos humanos, investigações de abusos por parte do Ministério Público Estadual e outros organismos estatais, concomitantes a novas dispersões dos usuários de crack pela cidade (Frúgoli Jr., 2013:49-50). Cabe ainda mencionar que as chamadas cracolândias também atualizam antigas representações estigmatizantes acerca dos moradores de rua, com meninos e meninas de rua, pedintes e mulheres em situação de prostituição que se fundem àquelas atribuídas aos usuários de crack, condensando e reproduzindo a partir dessa figura uma série de novas tensões sociais. ${ }^{6}$

5 No contexto carioca, o consumo de crack se espalhou mais tardiamente - os primeiros registros de venda e do surgimento de espaços em que a droga passou a ser consumida em público e de modo rotineiro datam de 2005 e 2006 (Barnes \& Rosales, 2011). A venda e o consumo de crack rapidamente transformaram as próprias dinâmicas do tráfico nas áreas em que se instauraram, gerando uma nova estrutura de gestão e de vendas da droga, mas também esforços cotidianos do próprio tráfico na ordenação dos espaços sob a sua influência, tendo em vista as novas territorialidades produzidas pelas tensões entre os fluxos e as permanências dos usuários de crack. No Rio de Janeiro, as concentrações de usuários de crack estão sobretudo no interior ou nos entornos de favelas. $^{7}$

6 Nesses lugares, as regiões com maiores e mais permanentes concentrações de usuários, cujas rotinas tendem a se cristalizar e a se consolidar embaladas em sua própria permanência no tempo e no espaço, são em geral rapidamente identificadas como cracolândias (agora no plural) pelos moradores das favelas, pelos próprios membros do tráfico, pela polícia, por assistentes sociais e psicólogos - que levam suas ações às cracolândias. Nos bairros ditos formais, em particular Glória e São Cristóvão, observamse concentrações itinerantes de usuários, sem que, no entanto, sejam consideradas cracolândias pelos atores sociais envolvidos em ou interpelados por essas 
territorialidades. Em suma, as cracolândias cariocas são registradas no plural, e elas tendem a remeter aos espaços no interior ou ao redor de favelas.

7 De um modo geral, são dinâmicas espaciais distintas do caso paulistano, em que tal densidade e visibilidade se reproduzem na região central (com uma nomeação geralmente no singular), mesmo que outros espaços venham aos poucos se tornando locais de uso regular do crack, sem que se configure necessariamente a mesma paisagem. Dessa forma, em São Paulo, o espraiamento do uso do crack guarda certa relação com dinâmicas de repressão que se articulam com os interesses do já mencionado projeto Nova Luz - lembrando que essas ações policiais se combinam, de modo conflitivo, com intervenções ligadas ao campo da saúde e da assistência social além de dinâmicas menos visíveis vinculadas à capilaridade do tráfico de crack em diversas outras áreas do contexto paulistano. ${ }^{8}$

Assim, tanto no Rio de Janeiro quanto em São Paulo, a ideia de cracolândia implica o estabelecimento de uma série de relações com diferentes agentes (tanto do Estado polícia, assistentes sociais e assim por diante - quanto da dita sociedade civil - ONGs, redes de pesquisadores em saúde pública, psicologia social e ciências humanas). Ou seja, as cracolândias não são meramente sinônimos de locais em que se vende e consome crack; elas se produzem justamente em seu reconhecimento como territorialidades específicas por diferentes atores, que a elas dirigem uma série de práticas - repressivas ou de assistência (ou até uma combinação de ambas) - ou então táticas cotidianas para lidar com elas, no caso do tráfico de drogas ou dos moradores mais antigos de regiões em que as cracolândias se instalam.

9 No Rio de Janeiro, as tensões produzidas entre a permanência e a itinerância das cracolândias por diferentes atores sociais se dá em escalas mais amplas do que em São Paulo. Tal territorialidade (e itinerância), neste caso, está diretamente relacionada a diversas intervenções ligadas à realização dos próximos Jogos Olímpicos, em particular as ações da UPP (Unidade de Polícia Pacificadora), ${ }^{9}$ e às obras urbanísticas do PACFavelas (o componente social e urbanístico do Programa de Aceleração do Crescimento do governo federal, implementado pelos governos estadual e municipal). Sua geografia itinerante está imbricada com o processo de implantação de UPPs na cidade. Havia, inicialmente, grandes concentrações de usuários de crack no Complexo do Alemão. A ocupação militar deste último, em novembro de 2010, produziu um inchaço no fluxo de usuários em aglomerações já estabelecidas (e reconhecidas como cracolândias) em outras favelas, como Jacarezinho, Manguinhos e algumas regiões da Maré. Com a ocupação militar das duas primeiras, em outubro de 2012, observou-se a intensificação das mesmas rotinas e territorialidades em outras favelas que já contavam com espaços localmente reconhecidos como cracolândias, como os Complexos da Maré e do Lins.

Em outras palavras, as cracolândias cariocas são também fenômenos que se mantêm além da cidade dita "pacificada". Trata-se de fluxos consideráveis de usuários (estimados em centenas nos finais de semanas) que, expulsos de regióes em que se inicia o processo de "pacificação", refazem suas rotinas e retomam os esforços territorializantes associados à prática constante do uso da droga em novos espaços. A própria itinerância dessas territorialidades acaba por produzir naqueles que antes se encontravam nesses locais (como moradores, comerciantes etc.) a sensação de que as cracolândias brotam rápida e espontaneamente em espaços intersticiais, quando o que se observa, no caso carioca, são deslocamentos de práticas, agentes, rotinas e 
sociabilidades ancoradas no uso do crack, para além das regiões em que vigora a política de "pacificação". ${ }^{10}$

11 Dada a combinação entre certa fixação territorial e as possibilidades de deslocamentos cuja extensão depende de fatores ligados, dentre outros, ao tipo de repressão a que tais usuários de crack são submetidos - sejam as cotidianas, sejam aquelas mais duradouras e de maior escopo - pretende-se explorar neste artigo o conceito de territorialidade, levando em conta seu caráter itinerante, móvel e provisório, bem como, neste caso, vulnerável e intersticial, embora isto não signifique, evidentemente, deslocalização ou mesmo desespacialização. Inspiramo-nos, com muitas mediações, no conceito de territorialidades itinerantes utilizado por Perlongher (1987) em sua pesquisa sobre sociabilidades homoeróticas masculinas na região central de São Paulo, em forte diálogo com os referenciais de Deleuze e Guattari (1972, 1980). Enfatizam-se principalmente as possibilidades de olhar ocupações do espaço urbano que combinem estrategicamente mudanças e permanências - ou sedentariedade e nomadismo, ou ainda captura e fuga, nos termos propostos por Perlongher (1987:185-194) - numa determinada área específica, tal como se davam, na sua pesquisa, as relações entre michês e clientes na área central de São Paulo.

Cabe também dizer que não se trata de uma exploração integral das propostas deste autor: não se pretendeu testar a ideia do código-território, que cruza determinados espaços que concentram agentes e práticas com nomenclaturas classificatórias que se difundem por diversos marcadores sociais da diferença (Perlongher, 1987:108-154), tendo em vista, inclusive, que as nomeações atribuídas ao menos aos usuários de crack não indicam variações significativas no tempo e no espaço, embora a ênfase nesses agentes e naqueles com quem se relacionam mereça atenção, isto sem falar que os percursos dos mesmos por outros espaços podem revelar novos aspectos significativos. 11

13 Partimos também da ideia de que tais territorialidades, embora proscritas, estigmatizadas e alvo de uma série de práticas disciplinares, não constituem propriamente um mundo isolado, mas envolvem uma série de relações, interações e conexões, nas quais os usuários de crack têm um papel proeminente, mas articulado a uma série de outros sujeitos, cujos arranjos dialogam com cada contexto particular e são marcados por variações situacionais (Foucault, 1977; De Certeau, 1994 [1980]; Velho, 2013 [1981]; Frúgoli Jr., 2012). Trata-se também de compreender dinâmicas que produzem tanto "territorialidade" quanto "itinerância". E tal caráter móvel pode levar à necessidade da análise das disputas entre as distintas (e com frequência conflitivas) territorialidades que se configuram nos espaços urbanos em que as próprias cracolândias tendem a se instalar.

14 Dado que essas territorialidades envolvem determinados usos de calçadas, ruas, praças e outros espaços, isto permite pensar como a observação de tais locais pode revelar dimensões públicas relevantes, tendo em vista o que efetivamente emerge desse conjunto de interações, e não com base em qualidades apriorísticas do espaço público (Joseph, 2005 [1998]). Nos enfoques deste artigo, como já adiantado, abordaremos um conjunto de intervenções urbanísticas mais abrangentes que infletem sobre tais espaços através de ações que incluem tentativas de controle ou expulsão desses atores sociais, ao mesmo tempo em que se busca reinventar significados de civilidade que se opõem às práticas sociais e espaciais em andamento. 
15 A comparação entre Rio de Janeiro e São Paulo ou entre Manguinhos e Luz ajudam na compreensão da emergência da(s) cracolândia(s) como objeto de investigação que, de distintas formas, se impuseram como temática relevante nas trajetórias das duas pesquisas aqui sintetizadas, a partir das quais construímos contrapontos elucidativos de algumas questões analíticas que pretendemos desenvolver. Em outras palavras, nossas investigações tinham escopos mais abrangentes que a(s) cracolândia(s) como objeto de análise, e o modo como estas últimas se impuseram como objeto de observação é por si só indicativo de como passam a constituir certas regiões urbanas.

No caso da pesquisa paulistana, tratava-se em seus primórdios da busca de problematização de uma polaridade muito recorrente na região da Luz, desde meados da década passada, entre Nova Luz (um projeto urbanístico abrangente e polêmico do poder local) e cracolândia (nomeação popular dada à região devido à considerável presença de usuários de crack em certas ruas), bastante ampliada a certa altura pela grande imprensa. Tal contraponto (inevitavelmente complementar) entre "revitalização" e “degradação", presente no plano de representações sobre a área central desde a criação da Associação Viva o Centro (Frúgoli Jr., 2000), concentrou-se a partir de então nesta região, sobrepondo-se a fronteiras fluidas entre vários bairros (Luz, Santa Ifigênia, Campos Elísios e Bom Retiro), cujas circunscrições territoriais imprecisas ficam ainda mais embaralhadas pelo modo como instituições do poder público definem seus campos de atuação. Assim, além da tentativa de instituir uma nova delimitação espacial supostamente marcada por dois campos em oposição, tal polaridade tendia a tornar invisível uma considerável parcela de agentes sociais de uma área tradicionalmente popular, ligada à geografia difusa da chamada Boca do Lixo moradores, comerciantes, frequentadores de certos bares e outros equipamentos de consumo, transeuntes etc. - o que levava, dentre outros fatores, à necessidade de um desvendamento etnográfico.

Durante a pesquisa de campo, emergiram os noias nas falas de muitos sujeitos contatados quando se referiam ao bairro ou à região, o que nos levou a prestar mais atenção aos usuários de crack do que a um espaço fixo que a ideia de cracolândia poderia a princípio designar, o que se desdobrou no predomínio da ideia de territorialidade sobre a de território. Ao longo da investigação, que enveredou por diversas temáticas, não apenas os usuários de crack acabaram por ganhar um olhar considerável, mas também os agentes envolvidos num campo relacional mais amplo dessa territorialidade (Frúgoli Jr., 2012).

No caso carioca, o trabalho de campo na região foi realizado a partir de dois projetos. $\mathrm{O}$ primeiro, iniciado em maio de 2010, tinha como objetivo acompanhar e documentar o processo de esvaziamento e demolição de uma antiga fábrica de laticínios, que fora ocupada em 2000 (Cavalcanti \& Fontes, 2011). Devido a uma grande enchente em 2010, a ocupação foi incluída no cronograma de obras do Programa de Aceleração do Crescimento, do governo federal, que já vinha transformando as favelas vizinhas à antiga fábrica desde $2008 .{ }^{12}$ O projeto previa a demolição de todo o espaço edificado do terreno - que incluía quatro grandes galpões e dezenas de casas de alvenaria construídas nos espaços livres do antigo complexo fabril - e a construção de um conjunto com 686 unidades habitacionais, cujas chaves seriam entregues a uma parcela das famílias residentes na ocupação.

19 A segunda pesquisa de campo na região fazia parte de um projeto mais amplo sobre os impactos da UPP em diferentes favelas da cidade - em que Manguinhos figurava como 
uma espécie de "caso controle", já que, na época, não possuía UPP, o que possibilitaria, portanto, uma escuta também dos efeitos remotos do programa de pacificação (Banco Mundial, 2012; Burgos et al., 2012). Assim, fez-se necessário, durante o trabalho de campo, enfocar as transformações então em andamento no espaço do complexo de Manguinhos, que eram implementadas pelas obras do PAC.

Em ambas as frentes de pesquisa, por mais que tentássemos ancorar as questões de campo nas transformações do PAC, as cracolândias e as mudanças que implicavam negociações cotidianas do uso do espaço em Manguinhos e seu entorno se impuseram como objeto de análise. Os cracudos eram onipresentes; dominavam tanto a paisagem urbana quanto a fala dos moradores. Qualquer opinião acerca dos rumos da cidade ou da vizinhança fazia referência a eles. Charges sobre o cotidiano dos ônibus com ponto final na região das cracolândias circulavam entre moradores da região pelo Facebook, e nelas os cracudos figuravam, explicitamente, como mais um elemento ou personagem do cotidiano dali, junto com o ônibus lotado, as crianças uniformizadas no trânsito casa-escola, e o pequeno comércio das avenidas do subúrbio.

21 Assim, a(s) cracolândia(s) e os cracudos ou noias apareceram nas pesquisas etnográficas como agentes concretos com os quais os demais agentes sociais se deparavam, e que de algum modo interagiam ou entravam em conflitos de diversas ordens que reverberavam particularmente sobre o espaço e seus usos. Essa linha de raciocínio leva, portanto, a uma indagação sobre o espaço mais amplo onde se situam as cracolândias em questão (e as relações sociais que o constituem). De novo, as experiências de campo são reveladoras de aspectos conjunturais que convergem para paisagens materiais assinaladas por ruínas. Tanto no caso da Luz quanto no de Manguinhos, as cracolândias se reproduzem ou surgem em meio a escombros de obras de grande escala, que compõem projetos mais amplos (políticos e urbanísticos) de ressignificação de certas regiões do espaço urbano.

O projeto da Nova Luz e as obras do PAC fazem parte de uma mesma lógica de produção da cidade, em que o Estado realiza investimentos em infraestrutura aliados a grandes esforços de "recuperação" de regiões consideradas degradadas, perigosas ou fora de seu alcance, com o objetivo último de tornar essas regiões permeáveis, ou atraentes para as forças do mercado. A esses esforços, somam-se estratégias de produção de novos sentidos simbólicos articulados às áreas em processo de intervenção - no caso da Luz, inicialmente a de "bairro cultural", posteriormente uma área mais ampla de intervenção, no caso de Manguinhos, de região "pacificada" a território "retomado" pelo Estado.

É certo que se trata de intervenções de escalas e em contextos marcadamente diferentes, em que os elementos de transformação urbana, a repressão policial e as redes de sociabilidade e militância política anteriores se articulam com sínteses diversas. Não obstante, há também uma semelhança marcada em certas paisagens e rotinas em torno das quais os conflitos sobre usos cotidianos locais se desdobram nos dois casos. A produção desses novos espaços gera escombros, e imprime uma temporalidade provisória a lugares outrora afeitos a rotinas relativamente estabelecidas. Há, em ambos os casos, um esforço de impor novos usos do espaço por meio de intervenções urbanas concebidas através de processos políticos em que a ausência de transparência em relação aos cronogramas, aos projetos de demolição e à realocação, além dos atrasos das obras tendem a instalar muitas incertezas. Nesses processos, paisagens marcadas por ruínas perduram por anos a fio, esgarçando as 
territorialidades e as rotinas que outrora constituíam esses lugares. Mas também se produzem novas apropriações e outros usos - dentre os quais se destacam a(s) cracolândia(s).

No caso da Luz, trata-se de um conjunto de intervenções urbanísticas em andamento ao menos desde a década de 1990 na região central de São Paulo, intervenções estas baseadas em ações que abdicam de um planejamento urbano mais abrangente e que se inscrevem num ideário de revitalização ou requalificação, com forte tendência à expulsão de moradores ou frequentadores das classes populares, e que mais recentemente vem buscando se apoiar na polêmica lei da concessão urbanística (aprovada em 2009), ${ }^{13}$ que confere poderes amplos e inéditos ao capital privado (Frúgoli Jr., 2000, 2012).

No caso de Manguinhos, vigora o que pode ser pensado como um "urbanismo pacificador", produzido a partir de programas em que o elemento de instauração de certa ordem pública idealizada vem a ser instituída pela suposta "presença do Estado". Aqui, a estética das intervenções em favelas as inscreve no espaço urbano de modo a espetacularizar e performatizar uma suposta "retomada" de territórios por meio da ocupação militar, que é também inscrita e assinalada nas intervenções urbanísticas em curso (Cavalcanti, 2013).

\section{Da cracolândia aos noias na região da Luz}

Nossas observações na região da Luz tiveram início em outubro de 2007, quando as primeiras demolições ligadas ao Projeto Nova Luz haviam ocorrido (no triângulo formado pelas ruas Mauá, Protestantes e Gen. Couto de Magalhães), sem que os atingidos por elas e a população do entorno tivessem uma ideia mais clara sobre os objetivos concretos das intervenções, embora em geral considerassem que as mesmas não levariam a uma mudança substancial do quadro urbano e social do lugar. Naquele momento, era possível encontrar usuários de crack nas ruas da área demolida - que se tornara mais deserta e, para muitos, mais insegura - mas a maior parte deles já estava mais concentrada na rua Helvetia e adjacências (como as praças Princesa Isabel e Júlio Prestes), a algumas quadras dali, fora da circunscrição do perímetro definido pelo projeto Nova Luz.

Desde o início, as interações da equipe da pesquisa ${ }^{14}$ com os usuários de crack nos espaços públicos se deram sobretudo através do acompanhamento das ações realizadas pela associação É de Lei, que atua, na linha da redução de danos, há anos na região. E foi na área da rua Helvetia que encontramos, em geral, as maiores concentrações de usuários com eles estabelecendo interações pontuais, ou então observando de perto relações construídas pelos integrantes da referida associação com eles, o que costuma envolver escutas sobre problemas (já havia então várias ações policiais em curso), convite para uma ida ao centro de convivência, entrega de preservativos, piteiras ou batom de cacau, atenção ou recomendações em relação a cuidados pessoais, ferimentos etc. Estes agentes haviam tido condições para a construção de um registro de mais longo prazo sobre tais usuários, com observação mais detida de certas trajetórias pessoais. É importante constar, de todo modo, que essas ações inserem-se num campo múltiplo de atuações das quais participam várias outras entidades, ligadas principalmente à Igreja católica e às Igrejas evangélicas, e que ganhou maior complexidade quando, a partir de 2009, passou a haver intervenções dos poderes 
públicos, tanto estadual quanto municipal, que combinavam ações policiais com outras ligadas prioritariamente ao campo da saúde.

Antes disso, ainda em 2007, foi possível fazer interações um pouco mais duradouras com os usuários de crack, embora marcadas por certa fugacidade, e das quais tentávamos extrair o que era possível quanto à forte heterogeneidade de situações observadas. De um modo geral, é possível notar que a ação da polícia os leva a sair rapidamente das calçadas onde estão situados, migrando para outro local próximo, por fim, em tempos variáveis, retornando aos pontos anteriores de concentração. Alguns seguranças privados também fazem, em menor escala, algum tipo de ação quanto à permanência e à circulação desses usuários. A maior parte deles consome o crack nas calçadas (vários ocultam a prática sob cobertores), embora haja também o uso de hotéis e pensões do entorno para tanto, além dos mocós em casas, sobrados ou prédios abandonados ou lacrados pela prefeitura.

Quase um ano depois (2008), a retomada de nossas observações evidenciava basicamente uma quantidade maior de usuários de crack nas ruas, ao mesmo tempo em que eram submetidos a uma repressão mais intensa, com a presença de policiais em carros, motos, a cavalo, à paisana, além da ação de seguranças privados ou até de certas casas equipadas com orifícios que lançam água nas calçadas. As interações com os usuários tornavam-se, assim, mais fugazes que as anteriores, já que eles eram obrigados a uma forte circulação que, no ano seguinte (2009), ganharia ainda mais intensidade. Um deles, ao passar perto de nós, comentou ironicamente que havia naquele dia "uma passeata de noias", o que parecia sintetizar dinâmicas então em andamento. Durante as interações, surgiu novamente uma sucessão de cenas para nós dramáticas, como uma moça grávida que consumia crack no chão, pessoas com ferimentos graves ou em condições físicas preocupantes, sem falar de muitas que tinham estado presas, e de dezenas de usuários que fumavam ao mesmo tempo, o que impedia alguma aproximação possível por parte dos agentes redutores de danos.

Apesar da rapidez das interações, era possível perceber que nem todos que estavam ali usavam necessariamente crack, e que nem todos estavam com o corpo ou as roupas marcados pela precariedade. Estes fatos relativizavam a ideia de que tal territorialidade fosse composta apenas por usuários desta substância ou por pobres e marginalizados. $\mathrm{O}$ termo noia (muito acionado "de fora para dentro") sugeria, entre eles, um tom de crítica moral. Certa vez um rapaz nos disse que fumava crack, mas que não era um noia, já que sabia como consumir (alternando com cuidados alimentares ou corporais) e que não ficaria deitado pelas ruas.

31 A partir de meados do ano seguinte (2009), configurou-se a "Ação Integrada Centro Legal", com uma repressão ainda mais acirrada, combinada com novas ações sistemáticas (embora com resultados pouco efetivos) no campo da saúde e da assistência social que, na prática, retomava os objetivos repressivos da "Operação Limpa", ocorrida em 2005, embora esta última se assumisse como claramente policial. Tal ação articulava-se aos interesses implícitos do poder local de remover essa população da área, dada a aprovação, na mesma época, da já mencionada lei de concessão urbanística que, caso levada à prática, poderia delegar à iniciativa privada um poder sem precedentes quanto à amplitude e ao escopo de intervenção urbana.

Dada a amplitude da operação, a imprensa passou a detectar a presença de usuários de crack em ruas da Barra Funda, Vale do Anhangabaú, Praça da República ou Praça Roosevelt; outras matérias apontavam o aumento da região da cracolândia, englobando 
Luz, Bom Retiro, Santa Cecília, República e Arouche (todas estas áreas pertencentes à área central da cidade). ${ }^{15}$ Esse espraiamento não seria propriamente novo, já que fora possível coletar dados sobre um fenômeno parecido, embora provavelmente menor em termos demográficos, no ano de $2000 .{ }^{16}$ De toda forma, numa visita ao Projeto Quixote que trabalha com crianças e adolescentes envolvidos com o crack, e que entendiam que a repressão em curso os obrigava a uma circulação vertiginosa pela cidade, o que dificultava o atendimento e levava o acesso ao crack para novas áreas urbanas - foi possível observar, no período em questão, uma concentração considerável de usuários de crack na rua Joaquim Gustavo, a maioria sentada no chão e com o cachimbo nas mãos. Quando policiais a pé se aproximavam vagarosamente, a maioria se deslocava na direção da Av. São João; 15 minutos depois, aproximadamente, vários deles já tinham retornado ao mesmo local.

Em janeiro de 2012, emergiu um novo episódio de repressões policiais sistemáticas, envolvendo Polícia Militar, a Rota, bombeiros, helicóptero, centenas de carros, dezenas de motos, cães farejadores e cavalos, com base na estratégia, como divulgado em inúmeras notícias da época, de causar "dor e sofrimento" aos usuários, forçando-os a buscar tratamento. Isto mostrava a determinação do poder público de remover a qualquer custo os usuários de crack daquela área urbana - numa intervenção que a princípio articularia ações combinadas entre várias secretarias - o que fez com que esta problemática, como já mencionado, ganhasse dimensão nacional, sobretudo por conta da polêmica da pretendida internação compulsória ou involuntária sob ordem judicial. ${ }^{17}$ Uma série de debates e de atitudes em múltiplos campos de saber e de ação foram impetrados no sentido da busca de outras alternativas.

Ainda em meados de janeiro, no bojo de todas essas polêmicas, foi organizado um ato de protesto contra a violência policial dirigida aos usuários de crack e a ausência de políticas públicas voltadas à população de rua e aos dependentes de drogas - o "churrascão na cracolândia", convocado por 43 entidades - com a participação de ativistas, usuários de crack, moradores, frequentadores e comerciantes da região e de outras partes da cidade, jornalistas, fotógrafos etc. Foi então possível o reencontro de várias pessoas que haviam participado da pesquisa na Luz abordada neste artigo. Apesar do clima de politização reivindicativa e até festiva, novas situações dramáticas ligadas à dinâmica cotidiana do lugar surgiram em certos momentos, como quando vários usuários se aglutinaram num trecho da rua Helvetia para receber pedras de um traficante (cena que se desenrolou bem próxima dos policiais) e alguns reclamaram veementemente de pessoas que os fotografavam. Mais tarde, um mocó de uma casa interditada na Al. Dino Bueno, usada por usuários de crack, foi aberta à visitação de todos que ali estavam, revelando-se um quadro altamente desolador.

Uma breve e recente visita à região atesta evidentemente a forte e duradoura concentração de usuários na área assinalada na confluência da rua Helvetia com a Al. Dino Bueno, ao lado de uma área onde se situava a antiga rodoviária de São Paulo, posteriormente um shopping atacadista de tecidos, que foi demolido em meados de 2010 para a futura construção de um teatro destinado à dança. Enquanto isso não ocorre, acentua-se um significativo caráter de abandono. Na atual conjuntura, com outra gestão local ligada ao PT, pairam indefinições sobre o futuro do projeto Nova Luz (interrompido, mas contratualmente ainda existente), dos encaminhamentos em relação aos usuários de crack (já se sabe o que não dá certo, mas não propriamente o que pode avançar em termos práticos) e para a região como um todo. 
Em pesquisa com diversos moradores da região (Frúgoli Jr. \& Chizzolini, 2012), cuja diversidade interna não será aqui aprofundada, fica patente que a presença dos usuários de crack pelas ruas leva à necessidade de uma série de estratégias para que se estabeleça uma relação com eles, o que passa pela produção de dádivas, cordialidade, evitação, tentativas isoladas de fazer com que usem o que ganham com alimentação e não com compra de crack, classificação das diferenças entre aqueles que se encontram na rua em condição precária (homem de rua, mendigo, noia, bêbado, trabalhador bêbado etc.). Em várias situações de pesquisas, residentes não evitavam as concentrações de usuários de crack, e alguns deles não os viam propriamente como perigosos. Muitos proprietários avaliam que a presença ou a ausência da concentração desses usuários implica diretamente na desvalorização ou na valorização do imóvel, respectivamente. De toda forma, foram mapeadas práticas violentas no interior de três edifícios pesquisados, envolvendo ilegalidades, ameaças, agressões, tráficos, lutas acirradas por recursos condominiais, negócios ilícitos e informais, prática microscópica de especulação imobiliária etc. Isto ajuda a explicar que, nesse quadro, nem sempre os noias são o principal problema ou fonte de temor.

\section{O crack, o PAC e a "Faixa de Gaza”}

Passemos agora às descrições etnográficas do contexto carioca. Desde os primeiros dias de janeiro de 2012, o terreno que outrora abrigara a fábrica vinha sendo cercado pela Policia Militar. O BOPE ocupara a frente do terreno, e seu veículo blindado, conhecido como "Caveirão", permanecia a postos na entrada principal. Todo o aparato militar justificava-se pelo fato de proteger os explosivos que teriam de permanecer em meio às estruturas da antiga fábrica nas 72 horas que antecediam a implosão, levada a cabo em 8 de janeiro de 2012. A operação de guerra se legitimava pelo fato de a antiga fábrica, tornada ocupação, mas conhecida como "comunidade", estar situada no entorno de uma região à qual a mídia vinha apelidando de "Faixa de Gaza" há décadas, em função dos constantes conflitos entre traficantes e policiais, mas também por históricas, senão traumáticas, demonstrações ostensivas de força pelos "bandidos" da região.

No entanto, a trama por trás do forte esquema de segurança da região nos dias que antecederam a demolição da antiga fábrica era mais complexa do que parecia a um olhar de fora. Nossa equipe estava em campo há quase dois anos, documentando o processo de esvaziamento do terreno e o consequente desmantelamento da ocupação que perdurara ali por mais de uma década, desde fins de 2000, e que chegara a abrigar 1.200 famílias em seus cinco edifícios e casas construídas nas margens do terreno triangular, cercado por altos muros para além dos quais se estendem duas linhas férreas.

No decorrer dos dois anos em que nossa equipe acompanhou o processo de esvaziamento dessa ocupação, a preocupação com os fluxos de "cracudos" havia sido uma constante para a líder comunitária da ocupação - e seus esforços por controlá-los foram se tornando cada vez mais fúteis, uma vez que os moradores esvaziavam suas casas deixando para trás objetos, roupas, móveis e, mais tarde, os acabamentos mesmos das casas (em particular, as louças de banheiros e as esquadrias das janelas), que iam sendo corroídos no decorrer dos esforços dos usuários para revender objetos em troca de pedras de crack nos circuitos de trocas das cracolândias. Quando nós chegamos ainda em 2010, ela sempre apontava os rastros deixados pelos usuários - copos de água 
mineral transformados em cachimbos improvisados, pequenos montes de lixo e restos de fogueiras - para nos assegurar que eram moradores que ali faziam uso da droga e que, portanto, ela nada poderia fazer, mas ali não havia "cracolândia", ou seja, as fronteiras da ocupação permaneciam sob seu controle.

Era importante para ela demonstrar que mantinha o controle espaço da ocupação. Nesse sentido, somava-se a outras falas sobre os "cracudos" e as "cracolândias" da região, que tendiam, de fato, a associar estas últimas a certa ausência de autoridade territorial. Na dita "faixa de Gaza", onde o tráfico perdurava sob uma única facção desde que estas se instituíram no começo dos anos 80 , as rotinas ligadas ao uso de crack apresentavam caminhos e espaços relativamente delimitados, e eram sistematicamente empurradas para além dos lugares estratégicos das rotinas do tráfico. Duas grandes cracolândias haviam se estabilizado na região: a primeira, ao longo da linha do trem no ramal auxiliar da Central, nas proximidades da estação do Jacarezinho, ou seja, sob a relativa proteção do território do tráfico, no que concerne à vulnerabilidade dos usuários em relação a operações policiais, mas fora do alcance ou do escrutínio mais direto dos traficantes - tratava-se de um espaço intersticial, cuja instabilidade constitutiva devido à própria disrupção periódica da passagem do trem a mantinha como territorialidade sempre provisória.

41 A segunda cracolândia da região, cujo foco central era inicialmente no "asfalto", ao longo de uma das avenidas principais do subúrbio carioca, foi "empurrada" para o interior de Manguinhos, após as obras do PAC terem desapropriado vários imóveis para a construção de uma creche e de uma praça. O movimento para o interior de Manguinhos se deu concomitantemente ao processo de ocupação militar do vizinho Complexo do Alemão. A intensificação do comércio de crack que se seguiu à ocupação do Alemão contribuiu para que esse deslocamento para o interior provocasse a constituição do que passou a ser visto como uma enorme cracolândia, que se espraiava ao longo de três campos de futebol localizados sob fios de alta tensão, dois deles construídos pelo PAC. Ali, centenas de usuários se recostavam nas muretas entre os campos e as novas calçadas do PAC. Dentro dos campos, camadas de lixo eram reviradas por cavalos e porcos, e alguns abrigos relativamente permanentes - cabanas improvisadas com fios e panos, mas mobiliadas com cadeiras quebradas e velhos sofás com estofamento corroído, atestavam a consolidação de certas rotinas, o que indicava uma acomodação, sempre provisória, daquela territorialidade naquele espaço.

Ao contrário do caso paulistano, em que a itinerância da cracolândia daquela territorialidade e naquele espaço tende a se dar em um perímetro relativamente circunscrito - e referimo-nos aqui à principal concentração de usuários de crack da cidade, não às ocupações mais pontuais que ocorrem em outros locais - as cracolândias cariocas têm sua configuração marcada por migrações bastante significativas. Daí a preocupação constante, na antiga ruína fabril, de o espaço configurar-se como cracolândia. A tarefa já era árdua quando o terreno triangular, de cerca de $50 \mathrm{mil} \mathrm{m}^{2}$, cercado por muros altos para além dos quais se espraiavam duas linhas férreas, contava apenas com uma entrada..$^{18}$ Com o acelerar das obras, em fins de 2011, foi aberta uma passagem para uma das linhas férreas, com a justificativa de facilitar a saída de escombros e a entrada de máquinas. Em menos de dois dias, uma nova boca de crack havia se instalado nas cercanias da entrada recém-aberta para o terreno, e o controle sempre precário do espaço da antiga fábrica se tornou, então, uma tarefa impossível. 
43 Foi nessas condições que a firma de engenharia responsável pela demolição do terreno encontrou a ruína da antiga fábrica. 0 grande desafio cotidiano para o andamento dos trabalhos residia não em qualquer ameaça do tráfico, mas nas próprias territorialidades que os usuários de crack iam produzindo para além das cracolândias já estabelecidas. Como o espaço havia sido incorporado aos itinerários cotidianos dos usuários - entre as "bocas", as cracolândias, seus abrigos provisórios e os locais de troca ou processamento de objetos a serem intercambiados nos mercados locais - havia uma preocupação generalizada com a instalação de uma cracolândia no próprio sítio que abrigava a ruína fabril em processo de demolição. A instalação ali parecia ser uma questão de tempo, segundo o consenso entre diferentes atores sociais envolvidos naquela situação.

À sensação reinante de transformações em curso acrescentavam-se aquelas precipitadas pela ocupação militar do vizinho Complexo do Alemão. A ocupação militar, com o objetivo da implantação de UPPs, teve dois grandes efeitos no Complexo de Manguinhos e no entorno da dita Faixa de Gaza: de um lado, o comércio de crack e o fluxo de usuários da droga se ampliaram; de outro, também a presença de novos "bandidos" ou estranhos nos becos e nas vielas contribuíram para o incremento de tensões no cotidiano dos moradores que compartilhavam aqueles lugares - eles mesmos também em mutação em função das obras do PAC.

Tratava-se, assim, de um cenário em que camadas de espaços provisórios se sobrepunham às rotinas que caracterizam o uso cotidiano dos locais; nesse sentido, territorialidades instauradas ao longo de décadas viram-se, no decorrer de dois anos, sujeitas a novos usos dos espaços por outras redes de atores, cujos projetos e investimentos nesses mesmos lugares inauguravam novas disputas. De um lado, o "urbanismo pacificador", com obras do PAC que faziam proliferar escombros e paisagens efêmeras, enquanto os usuários de crack ocupavam, através de vários fluxos, os interstícios dos novos espaços; uma vez concluídas as obras, os usuários ali se reinstalavam, com novos arranjos e conexões com outros espaços - os bares, as bocas, as passagens mais consagradas dos moradores da região. Na provisoriedade desse cenário, os fluxos relacionados às cracolândias tendiam a se alojar onde velhos e novos usos desestabilizassem antigas rotinas: em regiões de demolição ou em escombros das obras, ou seja, nos interstícios de outras territorialidades em processo de (re)acomodação.

Ao longo dos dias que antecederam a colocação dos explosivos, as tensões na ruína da antiga fábrica cresceram exponencialmente. Os edifícios seriam inicialmente demolidos por escavadeiras, deixando apenas a estrutura para ser derrubada pelos explosivos. 0 fato de os preparativos para a demolição ocorrerem nos últimos dias do ano, com o consequente esvaziamento do terreno nos feriados de Natal e Ano Novo, só contribuiu para a sensação de um controle precário do espaço. Os "cracudos" causavam pequenos e médios incêndios; eles entravam por qualquer brecha nos escombros e dilapidavam as sobras do edifício e dos pertences deixados para trás por antigos moradores, em meio a escavadeiras e tratores. Engenheiros, técnicos de demolição e operários exasperavamse a todo momento em função de relatos de "cracudos" que eram encontrados entre os entulhos, em áreas já em processo de demolição. Temia-se que eles pudessem detonar os explosivos, ou que já tivessem morrido ou sido soterrados sob os escombros das escavadeiras que preparavam os edifícios para a demolição da fundação. Mas à medida que o tempo passava, a exasperação ia se transformando em aversão por aquilo que era amplamente percebido como "praga" a ser repelida. 

controlava mais os acessos ao terreno. Nos primeiros dias de 2012, quando chegamos ao terreno, fomos interpelados por um antigo morador da ocupação, que então fazia as vezes de vigia, e que logo deixou claro que nosso acesso era garantido por ele. Intrigada, perguntei: "Então, você é o dono dessa ruína agora?". "Sim", disse ele. "De dia. À noite isso aqui vira um clip do Michael Jackson". E pelos próximos 40 minutos escutei incontáveis casos de "cracudos" que ele expulsara dali, de corpos de "cracudos" que carregara, de moças da zona sul perdidas na "cracolândia" a quem teria salvo, e assim por diante. $O$ "dono" da ruína antes trabalhara como vigia para a supervia - a companhia que administra os trens do ramal da região - e já acumulara bastante experiência em lidar com as rotinas e os incidentes causados pelos "cracudos", daí a oferta (informal) de trabalho pela firma responsável pela demolição Também ouvimos, a posteriori, relatos de que Marcelo seria não o vigia, mas uma figura-chave na organização de furtos de cabos de cobre dos trilhos da região. Para além de rumores e fabulações dele próprio, o que importa aqui é que ele entrava em campo com a missão expressa de dispersar uma possível "cracolândia". Assim, ele podia permitir os excessos noturnos dos "cracudos", mas de dia era necessário manter o espaço livre deles.

Antes mesmo de a fumaça da explosão baixar por completo, as figuras dos cracudos já eram visíveis no entorno do terreno. Ao que tudo indicava, Marcelo manteria seu emprego por algum tempo ainda.

O fato é que os conflitos em torno do espaço da antiga ruína fabril escapavam também das territorialidades do tráfico, o que se tornaria evidente alguns meses após a demolição da fábrica, quando, em junho de 2012, surgiram cartazes anunciando o fim da venda de crack no Jacarezinho. ${ }^{19} \mathrm{~A}$ explicação que corria pelos becos do Jacarezinho e de Manguinhos era que o objetivo do tráfico seria acabar com as cracolândias da região, como modo de evitar as constantes incursões policiais que elas atraíam em um momento em que o tráfico se encontrava acuado, com anúncios de uma possível implantação de UPP na região - que foi, de fato, ocupada em outubro de 2012.

\section{Breves conclusões}

Todo esforço comparativo exige cuidados redobrados para se evitarem generalizações apressadas, ainda mais porque São Paulo e Rio de Janeiro revelam não apenas espacialidades diversas, mas historicidades também singulares. Embora o uso de crack possa ocorrer em vários tipos de espaço, as pesquisas sobre os contextos paulistano e carioca enfocados neste artigo salientam um uso considerável de tal prática em locais públicos, ainda que neles haja variações significativas quanto à paisagem urbana $\mathrm{e}$ quanto às redes de relação nas quais estão envolvidos.

51 Neste artigo procuramos enfocar espaços públicos não apenas onde há algum uso de crack, mas aqueles nos quais a nomeação de cracolândia e a menção com certa recorrência a usuários de crack, tal como noias ou cracudos, é comum e regular.

52 Ambas as investigações, pautadas na observação continuada, permitiram que vislumbrássemos certos processos marcados por aproximações e similaridades no tempo e no espaço. Analiticamente, o modo como a(s) cracolândia(s) se impôs/ impuseram como objeto de investigação permite aventar a hipótese de que espaços provisórios, que ocupam os interstícios de territorialidades em processo de 
reacomodação espacial, simbólica e cotidiana, como os escombros de grandes obras de remodelamento urbano, constituem locais férteis para a constituição ou a consolidação de práticas e rotinas associadas ao uso do crack, e que são ou vieram a ser reconhecidas por diversos atores sociais como cracolândias. Ainda que no caso paulistano tal territorialidade dialogue com ocupações populares e marginais de longa data, ligadas à geografia imaginária da já citada Boca do Lixo, às quais se justapõem demolições recentes que propiciam ou reforçam tais ocupações do espaço.

Nesse sentido, vale também assinalar que o próprio surgimento das ditas cracolândia(s) passa a ser uma questão central para a gestão desses lugares, ou seja, a sua presença instaura a necessidade de uma "resposta" do Estado, através do discurso e das políticas públicas, de modo a contê-las. Isto, por sua vez, parece justificar a própria evidência da necessidade da presença recorrente da polícia como principal agente disciplinador nessas regiões - seja para amparar, mais recentemente, políticas de internação compulsória (cuja legitimidade também se constrói a partir de imagens consagradas da(s) dita(s) cracolândia(s) como algo a ser banido do espaço público), seja para simplesmente reprimir o uso do crack, embora muitas ações policiais tenham caráter mais performático que efetivo, ou se voltarem contra os usuários, mas não propriamente contra as dinâmicas do tráfico.

54 A itinerância mesma dessas territorialidades - das "passeatas de noias" ligadas às operações na área central de São Paulo às grandes migrações produzidas pela ocupação militar com vistas à implantação de UPPs no Rio de Janeiro - indica o fato, talvez óbvio, de que a(s) cracolândia(s) não se produz/produzem em um vácuo, mas sim em espaços compartilhados por outras territorialidades, às quais as rotinas da(s) cracolândia(s) se sobrepõem, gerando uma série de conflitos para além daqueles relacionados à repressão policial, e aponta também um conjunto de conexões com outros espaços e territorialidades que consolidam a própria ideia da(s) cracolândia(s).

55 Ainda sobre o tema da itinerância observada em ambos os casos, vale a pena diferenciar as que podem ocorrer cotidianamente num espaço mais circunscrito, sobretudo para retiradas estratégicas e momentâneas em face de investidas policiais, daquelas que se produzem envolvendo movimentos mais abrangentes pela cidade dos usuários de crack, ligadas a intervenções mais sistemáticas, cujos resultados revelam diferenças entre São Paulo e Rio de Janeiro. Isto porque a região da Luz constitui até aqui uma espécie de área para a qual a concentração contínua e simultaneamente de usuários converge e se dispersa (mesmo que os quarteirões ocupados possam mudar ao longo do tempo), o que reforça uma nomeação popular no singular, enquanto no Rio de Janeiro constata-se um caráter móvel de outra natureza, com áreas de concentração de usuários de crack mais espalhadas e com um certo movimento migratório, que suscita uma nomeação no plural.

Até o presente, a(s) chamada(s) cracolândia(s) mostram, em São Paulo e no Rio de Janeiro, territorialidades em forte relação com áreas urbanas onde predominam as camadas populares, embora na primeira metrópole se trate principalmente de bairros situados na área central, dotada de uma razoável infraestrutura urbana, porém diversificada, enquanto na segunda são basicamente áreas contíguas a favelas, marcadas por maior precariedade em termos de equipamentos urbanos, ainda que com graus distintos de consolidação. Isto exige que a abordagem tanto etnográfica quanto analítica seja capaz de lidar com espacialidades múltiplas e ancoradas em distintas tradições de estudo. Para além do desafio de lidar com um tema multifacetado, grave e 
de difícil enfrentamento, esta pode ser uma oportunidade de articular campos de investigação em geral separados quanto aos territórios predominantemente analisados.

\section{BIBLIOGRAFIA}

ADORNO, Rubens R.F. et al. 2013. "Etnografia da cracolândia: notas sobre uma pesquisa em território urbano". Saúde \& Transformação Social, 4 (2):4-13. Disponível em: http:// www.incubadora.ufsc.br/index.php/saudeetransformacao/article/view/2246/2646. Acesso em $15 / 10 / 2013$

ARANTES, Antonio A. 2000. "A guerra dos lugares". In: . Paisagens paulistanas: transformações do espaço público. Campinas: Ed. da Unicamp. pp. 103-129.

BANCO MUNDIAL. 2012. Bringing the State back into the favelas of Rio de Janeiro: understanding changes in community life after a disarmament and pacification process. Washington D.C.: World Bank.

BARBOSA, Antônio R. 2012. “Considerações introdutórias sobre territorialidade e mercado na conformação das Unidades de Polícia Unificadora no Rio de Janeiro”. Revista Brasileira de Segurança Pública, 6:256-265. Disponível em: http://www2. forumseguranca.org.br/node/31702. Acesso em:10/10/2013.

BARNES, Taylor \& ROSALES, Kristina. 2011. “New Jack Rio”. Foreign Policy. Disponível em: http:// www.foreignpolicy.com/articles/2011/09/14/new_jack_rio. Acesso em: 10/7/2013.

BOURGOIS, Philippe. 2003. In search for respect: selling crack in El Barrio. 2. ed. Cambridge/ New York: Cambridge University Press.

BURGOS, Marcelo et al. 2012. "O efeito UPP na percepção dos moradores das favelas". Desigualdade \& Diversidade, 11: 49-97. Disponível em: http://desigualdadediversidade.soc.pucrio.br/media/ 4artigo11.pdf. Acesso em: 10/11/2013.

CAVALCANTI, Mariana. 2009. "Do barraco à casa: tempo, espaço e valor(es) em uma favela consolidada”. Revista Brasileira de Ciências Sociais, 24(69):69-81. http://www.scielo.br/pdf/rbcsoc/ v24n69/05.pdf. Acesso em 10/7/2013.

2013. “À espera, em ruínas: urbanismo, estética e política no Rio de Janeiro da ‘PACificação”'. Dilemas. Revista de Estudo de Conflitos e Controle Social, 6 (2):191-228. Disponível em: http://revistadil.dominiotemporario.com/doc/DILEMAS62Art1. pdf. Acesso em: 22/11/2013.

CAVALCANTI, Mariana \& FONTES, Paulo. 2011. "Ruínas industriais e memória em uma 'favela fabril' carioca". História Oral, 14(1):11-35. Disponível em: http://www.revista.historiaoral.org.br/ index.php?journal=rho\&page $=$ article \&op=view\&path\%5B\%5D=221\&path\%5B\%5D=225\#. Acesso em: 10/10/2013.

DE CERTEAU, Michel. 1994 [1980]. A invenção do cotidiano 1. Artes de fazer. Petrópolis: Vozes.

DELEUZE, Gilles \& GUATTARI, Félix. 1972. L’Anti\&Edipe. Paris: Minuit.

1980. Mille plateaux. Paris: Minuit. 
DURHAM, Eunice. 2004 [1986]. “A sociedade vista da periferia”. In: . A dinâmica da cultura. São Paulo: Cosac Naify. pp. 377-407.

FELTRAN, Gabriel S. 2010. "Periferias, direito e diferença: notas de uma etnografia urbana". Revista de Antropologia, 53 (2): 565-610. Disponível em: http://www.revistas. usp.br/ ra/article/ view/37711/40440. Acesso em: 1/11/2013.

FOUCAULT, Michel. 1977. Vigiar e punir: nascimento da prisão. Petrópolis: Vozes.

FRÚGOLI JR., Heitor (ed.). 2012. Dossiê Luz, São Paulo. Ponto Urbe, 11. Disponível em: http:// www.pontourbe.net/edicao11dossieluz. Acesso em: 15/11/2013.

2000. Centralidade em São Paulo: trajetórias, conflitos e negociações em São Paulo. São Paulo: Cortez/ Edusp.

2005. "O urbano em questão na antropologia: interfaces com a sociologia". Revista de Antropologia, 48(1):133-165. Disponível em: http://www.scielo.br/pdf/ra/ v48n1/a04v48n1.pdf. Acesso em: 1/7/2013.

2013. "Variations sur un quartier du centre de São Paulo". Brésil(s). Sciences Humaines et Sociales, 3:49-67.

FRÚGOLI JR., Heitor \& CHIZZOLINI, Bianca B. 2012. "Moradias e práticas espaciais na região da Luz". In: Heitor Frúgoli Jr. (ed.). Dossiê Luz, São Paulo. Ponto Urbe, 11. Disponível em: http:// www.pontourbe.net/edicao11dossieluz/262moradiasepraticas espaciaisnaregiaodaluz. Acesso em: $22 / 11 / 2013$

FRÚGOLI JR., Heitor \& SPAGGIARI, Enrico. 2010. "Da cracolândia aos noias: percursos etnográficos no bairro da Luz”. Ponto Urbe, 6. Disponível em: http://www.pontourbe.net/edicao6artigos/ 118dacracolandiaaosnoiaspercursosetnograficosnobairrodaluz. Acesso em: 22/11/2013.

HIRATA, Daniel S. 2010. Sobreviver na adversidade: entre o mercado e a vida. Tese de Doutorado, Universidade de São Paulo.

JOSEPH, Isaac. 2005 [1998]. “A respeito do bom uso da Escola de Chicago”. In: Valladares, Licia P. (ed.). A Escola de Chicago: impactos de uma tradição no Brasil e na França. Belo Horizonte \& Rio de Janeiro: Ed. UFMG/ IUPERJ. pp. 91-128.

MACHADO DA SILVA, Luiz Antonio. 2010. “Mas afinal, qual é a das UPPs?”. Observatório das Metrópoles. Disponível em:http://www.observatoriodasmetropoles. ufrj.br/ artigo_machado_UPPs.pdf. Acesso em: 15/11/2013.

MISSE, Michel. 2006. Crime e violência no Brasil contemporâneo. Rio de Janeiro: Lumen Júris Ed. PERLONGHER, Néstor. 1987. O negócio do michê: a prostituição viril. São Paulo: Brasiliense. RUI, Taniele. 2012. Corpos abjetos: etnografia em cenários de uso e comércio de crack. Tese de Doutorado, Universidade de Campinas.

VALLADARES, Licia do P. 2005. A invenção da favela: do mito de origem a favela.com. Rio de Janeiro: Ed. FGV.

VELHO, Gilberto. 2013 [1981]. "O estudo do comportamento desviante: a contribuição da antropologia social”. In: Celso Castro; Karina Kuschnir \& Hermano Vianna (eds.). Um antropólogo na cidade: ensaios de antropologia urbana. Rio de Janeiro: Zahar. pp. 36-51.

ZALUAR, Alba. 2002. "A guerra sem fim em alguns bairros do Rio de Janeiro". Ciência e Cultura, 54(1):32-38. Disponível em: http://cienciaecultura.bvs.br/pdf/ cic/v54n1/v54n1a19.pdf. Acesso em: 15/11/2013. 


\section{NOTAS}

1. O que se diferencia, nesse sentido, do enfoque do estudo de Bourgois (2003), centrado nos agentes ligados ao tráfico de crack, num contexto (Hispanic Harlem, Nova York) em que não havia o uso do crack nas ruas, tal como observado comparativamente pelo próprio autor, quando visitou a cracolândia paulistana em 2010 (Ver: http://www.estadao.com.br/noticias/ impresso,nunca-vi-cracolandia-tao-sociavel-diz-expert,652090,0.htm. Acesso em: 27/8/2011).

2. O termo cracolândia (bem como noia ou cracudo) aparecerá em itálico ao invés de entre aspas, pois nesses casos nos referimos a ela como uma categoria analítica, elaborada a partir dos múltiplos modos com que os agentes a acionam, a depender de dimensões situacionais e relacionais do contexto pesquisado. Em outros casos (entre aspas ou mesmo sem aspas), reportamo-nos diretamente às falas dos nossos interlocutores.

3. Dialogamos, dessa forma, com temas tratados em fórum ocorrido na $28^{\mathrm{a}}$ Reunião Brasileira de Antropologia (São Paulo, 2012), intitulado "Questões em torno da chamada cracolândia", organizado por Heitor Frúgoli Jr., do qual participaram Taniele Rui, Mariana Cavalcanti e Antônio Rafael Barbosa.

4. Para uma notável reconstituição etnográfica das relações de usuários de crack com cenários urbanos através de suas práticas corporais cotidianas, ver Rui (2012).

5. Embora relevantes, há mapeamentos abrangentes em andamento sobre espaços marcados por usos de crack em diversas cidades brasileiras, que por vezes os nomeiam de cracolândia(s), algo em geral alardeado pela mídia, o que exige uma reflexão quanto aos riscos de uma proliferação antes de tudo lexical, que pode até auxiliar a instituir uma realidade mais grave que a efetiva (ver, p. ex., os resultados parciais de uma pesquisa na Fiocruz sobre cenários de crack em http:// www.estadao.com.br/ especiais/cenarios-do-crack,157744.htm (Acesso em: 21/8/2013), em que vários redutos de uso de crack são chamados de cracolândia). Em suma, usos de crack e cracolândia não são sinônimos.

6. No debate "Nem cracolândia nem Nova Luz", ocorrido em 10/6/2013 na Casa da Cidade (São Paulo), o atual subprefeito da Sé, Marcos Barreto, criticava a iniciativa de mais de 500 moradores de Santa Cecília (bairro da área central paulistana) contra a instalação, no bairro, de um centro de atendimento de moradores de rua; tais residentes se valem do argumento do possível surgimento de uma nova "cracolândia" (ver sobre o assunto, http://www1.folha.uol.com.br/ cotidiano/2013/06/1289361-centro-social-para-morador-de-rua-provoca-discordia-em-santa-

cecilia.shtml [Acesso em: 21/8/2013]); para ele, a droga que predomina nas ruas seria o álcool, não o crack.

7. Sobre a territorialização do tráfico de drogas no Rio de Janeiro, ver Zaluar (2002) e Misse (2006).

8. Predominam em São Paulo estudos sobre usuários de crack, não propriamente sobre os traficantes, embora se possa dizer que alguns agentes alternem situacionalmente ambas as condições, sem falar da partilha de pedras de crack entre vários usuários, ligadas a dinâmicas de reciprocidade entre os mesmos. Sobre dinâmicas mais abrangentes do tráfico em São Paulo, sobretudo nas periferias, ver Feltran (2010) e Hirata (2010).

9. Para problematizações instigantes sobre as UPPs, ver Machado da Silva (2010) e Barbosa (2012). 10. O caso da ocupação da favela Santo Amaro, no Catete, é emblemática dos esforços do atual governo do estado em manter as cracolândias para além das fronteiras da cidade "pacificada" ou "olímpica". Como o tráfico na região se encontrava bastante enfraquecido, não houve ocupação com vistas à instalação de uma UPP na região. No entanto, em maio de 2012, a favela foi ocupada pela Força Nacional de Segurança com o objetivo manifesto de reprimir as cracolândias da região.

11. Outra referência vem da noção de ocupações flexíveis e conflitivas do espaço urbano em Arantes (2000). 
12. Como ocorreu em outras ocupações de antigos espaços fabris na região, o projeto previa o esvaziamento da ocupação e a realocação temporária de seus moradores, enquanto seria construído o conjunto habitacional ao qual eles seriam reconduzidos.

13. Ver mais detalhes a respeito nas falas de Mariana Fix em http://www.redebrasilatual.com.br/ cidades/2012/03/para-especialista-operacoes-urbanas-da-prefeitura-de-sp-sao-frentes-deexpansao-do-mercado-imobiliario. Acesso em: 20/10/2013.

14. É com referência à experiência desta equipe paulistana, dividida em distintas linhas de investigação e coordenada por Heitor Frúgoli Jr., que esta seção do texto utiliza a $1^{\underline{a}}$ pessoa do plural. Na próxima, esta $1^{\underline{a}}$ pessoa do plural se referirá às duas equipes de pesquisa coordenadas por Mariana Cavalcanti. Os autores deste texto não estiveram juntos em campo em nenhum momento.

15. Para mais detalhes sobre o amplo material de imprensa coletado a respeito, ver Frúgoli Jr. e Spaggiari (2010).

16. Ver, a respeito, Folha de São Paulo, "Prostituição e drogas afligem Santa Cecília", de 23/1/2000, p. 4-1.

17. A internação compulsória permite que alguém seja internado para tratamento psiquiátrico contra a própria vontade e sem a necessidade de autorização familiar, desde que solicitada pelo médico psiquiatra e determinada pelo juiz competente. Isto foi praticado significativamente a partir da já mencionada "Ação Integrada Centro Legal" (2009) na região da Luz (ver, a respeito, http://www.saopaulo. sp.gov.br/spnoticias/lenoticia.php?id=225660. Acesso em: 20/10/2013), e ganhou forte visibilidade a partir dos eventos de janeiro de 2012 no mesmo local.

18. Para os moradores da ocupação, esta característica era decisiva, uma vez que mantinha o terreno relativamente livre das dinâmicas mais ostensivas do tráfico de drogas das favelas do entorno, já que tornaria os "bandidos" presas fáceis em inevitáveis incursões policiais. A ocupação consistia em certo "oásis" em meio à chamada Faixa de Gaza.

19. O fato foi, inclusive, noticiado na coluna do jornalista Ancelmo Gois no jornal o Globo, com uma foto-legenda de um dos cartazes. Ver detalhes em http://oglobo.globo.com/rio/ancelmo/ posts/2012/06/19/ trafico-proibe-venda-de-crack-em-favelas-do-rio-451154.asp. Acesso em: $30 / 7 / 2013$.

\section{RESUMOS}

$\mathrm{O}$ artigo parte de um desvendamento etnográfico da(s) chamada(s) cracolândia(s) paulistana e carioca, com o intuito de lançar um olhar antropológico sobre determinadas dinâmicas relacionais e espaciais urbanas. Para tanto, detemo-nos sobre os modos como se constituem como territorialidades itinerantes, em São Paulo e no Rio de Janeiro. A comparação sugere que a "itinerância" mesma da(s) cracolândia(s) aponta o fato de como elas se produzem em espaços constituídos por outras territorialidades em disputa - em particular, no contexto de grandes intervenções urbanas que visam ressignificar certas regiões das cidades em questão - e ainda para como as rotinas e as disputas em torno da(s) cracolândia(s) geram uma série de conflitos para além daqueles relacionados à repressão policial, produzindo também conexões com outros espaços.

The article builds upon an ethnographic unraveling of the so-called cracolândia(s) of São Paulo and Rio de Janeiro with the purpose of anthropologically grasping spatial and relational urban 
dynamics. We do so by reflecting upon how the cracolândia(s) constitute themselves as itinerant territorialities in Rio de Janeiro and São Paulo. The comparison suggests, first, that the cracolândia(s)' "itinerancy" itself point to how they are constituted in spaces woven by other disputing territorialities in the context of large scale urban interventions aiming to re-signify particular areas of the cities in question. Secondly, we argue that the social and daily routines and disputes surrounding the cracolândia(s) themselves produce a series of conflicts beyond those related to police repression, thus also producing connections to other spaces.

\section{ÍNDICE}

Keywords: uses of the space, territoriality, crack, itinerancy

Palavras-chave: usos do espaço, territorialidade, crack, itinerância

\section{AUTORES}

\section{HEITOR FRÚGOLI JUNIOR}

USP Heitor Frúgoli Jr. é professor do Departamento de Antropologia da FFLCH-USP, coordenador do Grupo de Estudos de Antropologia da Cidade (GEAC-USP), pesquisador do CNPq, integrante do Núcleo de Apoio à Pesquisa "São Paulo: cidade, espaço, memória" (USP) e conselheiro do Condephaat (2013-2014).Contato: hfrugoli@uol.com.br

\section{MARIANA CAVALCANTI}

CPDOC / FGV Mariana Cavalcanti é professora do CPDOC/FGV, pesquisadora do Laboratório de Estudos Urbanos (LEU/CPDOC-FGV) e integrante do conselho deliberativo da Casa

Fluminense. Contato: cavalcanti.m@gmail.com 